\title{
Permanent LMN denervation of human skeletal muscle and recovery by h-b FES: management and monitoring
}

\author{
Helmut Kern (1), Roberto Stramare (2), Leonora Martino (2), Riccardo Zanato (2), \\ Paolo Gargiulo (3), Ugo Carraro (4)
}

(1) Ludwig Boltzmann Institute of Electrical Stimulation and Physical Rehabilitation, Department of Physical Medicine and Rehabilitation, Wilhelminenspital Wien, Austria; (2) Department of Diagnostics and Special Therapy, University of Padova, Italy; (3) Clinical Engineering and Information Technology, Landspitali - University Hospital, Reykjavik, Iceland; (4) Laboratory of Translational Myology, Department of Biomedical Sciences, Interdepartmental Research Center of Myology, University of Padova, Italy

\begin{abstract}
Denervation of a defined skeletal muscle is due to lower motor neuron (LMN) or peripheral nerve lesions that have major consequences on the muscle tissue. After early atrophy, the midand late-phases presents two very contrasting myofibers populations: beside those severely atrophic with internalized groups of myonuclei, large fast-type muscle fibers continue to be present 4 to 6 years after Spinal Cord Injury (SCI). Recent results of rat experiments provides the rational basis for understanding the residual functional characteristics of the long-term denervated muscle and the molecular explanation of its ability to respond to home-base functional electrical stimulation (h-b FES) using custom-designed electrodes and stimulators. Further outcomes of the Vienna-Padova ten-year collaboration are: 1. a world-unique MyoBank of muscle biopsies and 2. improved imaging procedures (Color Computer Tomography (CT) scan and Functional Echomyography), all demonstrating that h-b FES induces improvements in muscle contractility, tissue composition and mass, despite permanent LMN denervation. The benefits of h-b FES could be extended from patents suffering with complete Conus-Cauda Syndrome to the numerous patients with incomplete LMN denervation of skeletal muscles to determine whether h-b FES reduces secondary complications related to disuse and impaired blood perfusion (reduction in bone density, risk of bone fracture, decubitus ulcers, and pulmonary thromboembolism). We are confident that translation of the results of a clinical experiment, the EU Project RISE, to the larger cohort of incomplete LMN denervated muscles will provide the wanted results.

Key Words: LMN denervation, human skeletal muscle, managements, monitorings, h-b FES, Color CT scan, ultra sonography, Functional Echomyography
\end{abstract}

European Journal Translational Myology - Myology Reviews 2010; 1 (3): 91-104

1. Diagnosis of complete LMN muscle denervation in SCI and nerve lesions

2. The multi-stage response of muscle tissue to $L M N$ lasting denervation

3. Lasting ability to respond to Functional Electrical Stimulation

4. New imaging tools for muscle monitoring

5. Perspectives

Lower motor neuron (LMN) muscle denervation is a major clinical and experimental problem that attracted attention of biologists, physiologists and of the medical community even before the modern scientific era. The major issues for decades have been the nature of the neurotrophic influence and the denervationreinnervation constrains. A principal query was whether there is a trophic function of the neuron that is distinct from its role in impulse conduction and transmission, the neurothrophic hypothesis, a concept suggested by the centuries-old question of Prochaska (1784), cited in Gutmann, 1962 [44]. Much of this has been excellently reviewed by Midrio [77] and Carlson [23]. In the medical literature other major issues are the neurodegenerative disorders, where partial muscle 


\section{h-b FES of denervated muscle: management and monitoring}

European Journal Translational Myology - Myology Reviews 1 (3): 91-104, 2010

denervation and reinnervation occurs concomitantly to the muscle disease process [22,110]. The ethiopathogenic analyses of these processes are difficult since pathomechanisms of denervation ought to be distinguished from those of a progressively insufficient reinnervation [29]. We will focus here to the special case of long-standing complete denervation of an anatomically defined muscle after lower motor neuron complete spinal cord injury and traumatic or iatrogenic peripheral nerve lesions. The potential of home-based Functional Electrical Stimulation (h-b FES) to rescue permanent denervated muscle from its progressive degeneration will be also described.

\section{Diagnosis of complete LMN muscle denervation in SCI and nerve lesions}

LMN denervation of limbs occurs when there are trauma to spinal cord, roots and peripheral nerves. Examples are spinal cord with concomitant root damage, brachial plexus palsy and sciatic nerve injury. Reinnervation, if it occurs, can take more than a year, during which time-span the affected muscles become severely atrophic and fibrotic, impairing the synaptic processes.

Atrophy of leg muscles is particularly severe when the injury destroys all their lower motor neurons and, hence, the contacts between motor neurons and muscle fibers. In this case, within weeks muscles become unable to sustain tension during tetanic contractions induced by electrical stimulation $[6,33,68]$. Within months, in case of irreversible complete injury of human Conus Cauda, the atrophying muscles of right and left legs are no longer excitable by standard commercial electrical stimulators [45]), [104]), [82] because they underwent severe disorganization of contractile elements (myofibrils) and of the excitationcontraction coupling (ECC) apparatuses [18,55,57,58]. Finally, after several years of LMN denervation $[55,66,89]$ muscle fibers are almost completely replaced by adipose and fibrous tissues. These severe functional and structural changes of muscle tissue are not present in patients presenting with upper motor neuron (UMN) lesions even 20 years after thoracic level SCI [61].

Differential diagnosis is trivial when SCI is due to vertebral dislocation at the thoracic spine, but larger trauma of the lumbar and ischiatic regions complicated by ischemic and infection necrosis of the cord may extend the damage to large segments of the medulla and of the nerve roots. In these cases the diagnostic problems are related to "completeness" of the LMN denervation, while the complete anesthesia of the legs and of the pelvic sphincters grants demonstration of a complete transverse spinal cord injury (grade A of ASIA scale).

To avoid problems in interpreting clinical results related to residual LMN innervation, we designed and implemented, firstly, a cross-sectional study [55] and then a longitudinal prospective study $[57,58]$ the European RISE Project: Use of electrical stimulation to restore standing in paraplegics with long-term denervated degenerated muscles (Contract No: QLG5CT-2001-02191) that recruited 25 paraplegic patients specifically selected because of complete denervation. The RISE patients were assessed before and after one and two years of home-based Functional Electrical Stimulation (h-b FES) by clinical, functional, imaging and muscle biopsy analyses. Dedicated diagnostic protocols were designed and implemented (Test electrical stimulation, Needle Electromyography, Brain Motor Control Assessment, Transcranial and Lumbosacral Magnetic Stimulation, and Color CT scan) to demonstrate "completeness" of LMN denervation of right and left quadriceps muscles before and during the two years of the study [56,62-64]. Twenty patients completed this longitudinal study $[57,58,63]$. The fact that the quadriceps of these patients were completely denervated before the beginning of h-b FES, and that they remained denervated also during and after the two years of training have been carefully tested and fully demonstrated employing the below assessments. In particular, the threshold of excitability of quadriceps muscles never increased to a level which allowed them to respond to standard commercial electrical stimulators, which can elicit muscle contraction through the nerve. Furthermore, the Color CT scans demonstrate a symmetric atrophy-degeneration of left and right thighs before h-b FES, and a symmetric recovery at both one and two years of training [58]. All together, these are sound evidence pointing to a complete lack of prior innervation and/or reinnervation during the h-b FES training. We will describe later these new imaging methods developed during and after the RISE study that we are extending to the more frequent cases of minor residual innervation and/or reinnervation.

\section{The multi-stage response of muscle fibers to long- lasting denervation}

The complex response of muscle tissue to denervation is one of the most described and experimented topics in muscle physiology and pathology. One of the important conclusion of studies published in the book “The Denervated Muscle”, edited by Ernest Gutmann in 1962 [44], is that after a certain period of time (6 months in the rat), denervated muscle undergoes some irreversible changes that inhibit its full restoration even after reinnervation. Works on a different experimental model, free autotransplant, lead to the same conclusion: rat muscle denervated up to 2 months is restored as well as grafts of control muscles, but between 2 and 7 months of denervation, the restorative capacity decline continuously before leveling out at a very low level at 7 months of denervation [23]. These pioneering observations were translated to macroscopic 


\section{h-b FES of denervated muscle: management and monitoring}

European Journal Translational Myology - Myology Reviews 1 (3): 91-104, 2010

behavior of denervated human muscle and his potential for reinnervation, establishing a dogma that continues to influence clinical managements of muscle denervation.

Despite countless publications, new studies in animals and humans are enlightening several unrecognized characteristics and mechanisms of the complex processes that occur during permanent LMN denervation of muscle tissue. These results are strengthening the rational basis of h-b FES to maintain/recover permanently LMN denervated muscles, opening also new options in regenerative medicine and reconstructive surgery.

Over the years there has been a good deal of interest for the use of functional electrical stimulation (FES) to restore structure and function of the limbs of paraplegic subjects $[42-44,82,106]$. In addition to the loss of voluntary movements and then spasticity, spinal cord injury that involves damage to upper motor neurons (that is, in patients in which muscles are still connected to lower motor neurons and the reflex arches are intact and often overactive) loss of voluntary contractions results in muscle atrophy and shortage of oxidative metabolism in the corresponding muscles, which, thus, generate less force in response to electrical stimulation. Muscle atrophy, however, remains stable, as we described in long-term paraplegics with complete upper motor neuron lesion from 3- to 20-years [61].

In sharp contrast are the features that are presented by the muscles after those types of spinal cord injuries that involve lower motor neurons because this causes actual denervation of the affected muscles. The disease process is particularly severe when a complete transverse spinal cord injury involves all the lower motor neurons innervating the thigh muscles. Complete LMN denervated muscles, indeed, are soon fibrillating and then unable to sustain tension during tetanic contractions induced by electrical stimulation [33]). Afterwards, they become unexcitable with commercial electrical stimulators, so that the long-lasting severe atrophy of the permanently inactive muscles is irreversibly worsened by substitution of myofibers with adipocytes and collagen [44,55,57].

Lasting muscle atrophy

Additional effects of long-term (in terms of years) LMN denervation of human muscle we recently described were, however, unexpected. In contrast with the well known rodent model (see above), one-year after spinal cord injury the LMN denervated human muscles still present simple atrophy. As was described in the rabbit model (see above), in a 60-case series of human vastus lateralis muscle biopsies from subjects suffering traumatic SCI, we observed that human muscle fibers undergo atrophy, not degeneration oneyear after LMN denervation [55,57], confirming and extending preliminary results of prospective bioptic studies of human free flap muscle transfers, which showed that at nine-month after surgery the denervated muscle fibers only decreased in size [53].

On the other hand, characteristic denervation-induced muscle fiber disorganization is documented by electron microscopy, much earlier than severe atrophy in both animal models $[9,10]$, and humans $[18,55,57]$, thus, explaining the early functional impairments of the LMN denervated muscle.

In humans, severe tissue degeneration at microscopic level starts only during the second year of SCI, fibrofatty muscle substitution being accompanied by other cellular processes: i) countless severely atrophic muscle fibers with nuclear clumping; ii) "swollen" fast-type muscle fibers; and iii) myoblast proliferationdependent muscle fiber regeneration (myotubes, NCAM- and MHCemb-positive "young” fibers and large onion-like muscle fibers).

Severely atrophic muscle fibers with nuclear clumps

Severely atrophic human muscle fibers with nuclear reorganization in central clumps fill the, seemingly, loose connective intramuscular tissue in between 3 and 5 years post-SCI [59]. These severely atrophic LMN denervated human muscle fibers had completely lost their myofibrillar apparatus and the coil distribution of myonuclei that are relocated in groups (nuclear clumps) in the center of the amyofibrillar muscle fiber. Immunohistochemistry with anti MHCslow shows that many of the severely atrophic myofibers are of slow type, thus demonstrating that they are adult fibers surviving denervation [2].

Human denervated muscle fibers undergo long term degeneration, but some paraplegic human muscles continue to display among countless small fibers, myofibers larger than normal (hypertrophic muscle fibers or "big cells"). Whether, these big cells are related to residual innervation/reinnervation or they represent one of the transient stage of the postdenervation atrophy/degeneration process has been debated since the early observations of Gutman [44]. Some of the large muscle fibers, so called onion-like myofibers, are the outcome of the regenerative potential of long term denervated muscle (see below). By light and electron microscopy we showed that the true "big cells" are neither the results of residual innervation or sparse reinnervation [15]. Immunohistochemical analyses of distrophin and $\mathrm{N}$ CAM, two sarcolemmal proteins, and the ultra structural evidence of severe disorganization of the contractile and the excitation-contraction apparatuses confirm that the paradoxical fast type "big" fibers in the long-standing denervated muscle are actually denervated. In spite of the fact that the extra-synaptic NCAM stainabilty [30] disappear a few months after SCI, the "big cells" are characterized by positive molecular markers of denervation, that is, the differential stainabilty of their dystrophin molecule by 


\section{h-b FES of denervated muscle: management and monitoring}

European Journal Translational Myology - Myology Reviews 1 (3): 91-104, 2010

anti-C and anti-N terminals [15]. Dystrophin glycoprotein complex dysfunction was demonstrated to occur in severely atrophic muscle fibers of cancer cachexia [1]. Furthermore, the peculiar ultra structural disarrangements of sarcomeric and membrane structures provides the final evidence that the "big cells" ("swollen cells", indeed) are denervated, distinct from normal and disused (due to UMN lesion) muscle fibers. While the large muscle fibers are more frequent in human muscle biopsies three to five years from SCI, it remains to be determined whether their higher content in some human muscle biopsies is related to subjects' back-ground genetics, to the extent of passive stretching induced by rehabilitation therapies, or to more combined factors.

Satellite cell activation, replication and fusion produce regenerated muscle fibers up to the 10th year of LMN denervation

In the human denervated muscles of the RISE cohort around $2 \%$ of the muscle fibers robustly express embryonic myosin heavy chains, a sound marker of regenerative myogenesis. This had also been demonstrated in rodents even after a year-long permanent denervation in both hemi-diaphragm and leg muscles $[26,28,80]$, and then confirmed in human up to 20-year after LMN denervation both without and with Functional Electrical Stimulation, which effectively reverts long-term atrophy and conceivably maintains the mass of regenerated myofibers [27,54]. Strong corroborating evidence was collected analyzing expression of myogenesis-related genes in denervated rat muscles [4,70,98].

Beside in LMN denervation due to SCI, regeneration of muscle fibers in human LMN denervated muscle had been reported in cases of free microvascular muscle transfers up to 4 years after surgery, when activation of satellite cells was evident [52,53]. In muscle biopsies harvested from three and more years after surgical transplant of free muscle flaps, among small muscle fibers, MHCemb-positive myofibers were demonstrated by the specific monoclonal antibody [97].

Further evidence of regenerated myofibers in LMN denervated muscle could be collected by light and electron microscopy. Beside activated satellite cells and myotubes [54], large onion-like muscle fibers are the evidence of the incomplete fusion of myotubes during aneural regenerative events. This has been demonstrated to produce several branched myofibers, when seen in transverse section, inside the remaining basal membrane of a dead myofiber in both rodents $[20,26,80]$, and humans $[27,54]$.

Thus, we conclude that human muscle fibers survive permanent LMN denervation much longer than generally accepted by means of both molecular and cellular mechanisms, which provide the rationale to plan research aimed to recover long-term denervated muscles by electrical stimulation combined with cellular approaches.

\section{Lasting ability to respond to Functional Electrical Stimulation}

All together, previous results leave a significant window of intervention for electrical stimulation to avoid degeneration of the LMN denervated muscle. To counteract the progressive changes that transforms muscle into an unexcitable tissue unable to generate force (using standard commercial stimulators from 6 months onward), in the past 20 years Clinicians and Engineers developed in Vienna novel rehabilitation concepts and devices for paraplegic patients with bilateral and complete LMN denervation of the lower extremity due to complete lesion of the Conus Cauda [54]. This new strategy became possible thank to the development and optimization of new stimulation equipments for home-based functional electrical stimulation (h-b FES). They have been specifically designed to reverse longstanding and severe atrophy of LMN denervated muscles by delivering high-intensity and long-duration impulses that can directly elicit contraction of denervated skeletal muscle fibers in absence of nerve endings [13,47,60,65,73,75,76]. These new stimulators and the large surface electrodes needed to cover the denervated muscles were developed by the Center of Biomedical Engineering and Physics at the Medical University of Vienna, Austria.

Meantime specific clinical assessments and training strategies were developed at the Wilhelminenspital Wien, Austria [54-67]. The results of this rehabilitation strategy for LMN denervated muscle were validated by the scientific achievement of a 5-year European Project, the EU Commission Shared Cost Project RISE: Use of electrical stimulation to restore standing in paraplegics with long-term denervated degenerated muscles.

Before our recent results based on functional and structural analyses, in particular, Color CT scan and light and electron microscopy of muscle biopsies harvested before and after 2 years of h-b FES, functional electrical stimulation was believed to be effective only when started early after LMN lesion, and useful only to delay muscle atrophy, since long-term denervated muscles do not respond even with twitch contraction, when stimulated by surface electrodes and standard commercial electrical stimulators developed for innervated muscles.

The results of the EU RISE Project, and of the related animal research, provide different perspectives. Twenty out of 25 patients completed a 2 years h-b FES program [57,58], which resulted in: 1. significant increase of thigh muscle size and of the muscle fibers, with striking improvements of the ultra-structural organization of contractile material; 2 . significant increase in muscle force output during electrical 


\section{h-b FES of denervated muscle: management and monitoring}

European Journal Translational Myology - Myology Reviews 1 (3): 91-104, 2010

stimulation (knee extension torque); 3. the recovery of quadriceps $\mathrm{m}$. force was sufficient to allow compliant subjects to perform FES-assisted stand-up and stepping-in-place exercises; 4 . ultra structural analyses demonstrated that the shorter was the time elapsed from SCI to the beginning of h-b FES, the larger were the number and the size of recovered fibers. The study demonstrates that h-b FES of permanent LMN denervated muscle is an effective home therapy that results in rescue of muscle mass and tetanic contractility $[18,55,57,58]$. Important benefits for the patients are the improved cosmetic appearance of lower extremities, the enhanced cushioning effect for seating $[18,55,57,58]$ and the early result of impressive reduction of the leg edema [17]. The last observation is supported by changes of the capillary networks observed in the muscle biopsies harvested from subjects suffering with long-lasting LMN denervation before and after h-b FES [94] and thoracic level SCI [71,72,91-93,95].

While the majority of paraplegics suffer of upper motor neuron damage by thoracic/lumbar traumatic SCI, and thus central muscle atrophy and spastic paralysis, less numerous are the patients who had experienced lower motor neuron damage by traumatic lesion of Conus Cauda, and thus present permanent LMN and radicular damage with loss of the nerve supply to the affected limbs.

These subjects develop flaccid paralysis of the tight skeletal muscles (Conus Cauda syndrome) and presents severe secondary medical complications of bone and skin.

During the first years after lesion, these LMN denervated patients show skeletal muscle fibre atrophy with frequent multiangular aspect, but finally in longstanding paraplegia muscle fibres are severely atrophic and numerous degenerated fibres are substituted by adipose and fibrous tissues $[55,57,58]$. Modifications of capillaries and arteriole in denervated human muscle were firstly described by Bowden et al, [21]. Thereafter, experimental studies in animals demonstrated that blood flow and oxygen consumption increased immediately after denervation as the result of damage to sympathetic vasoconstrictor fibres, and decreased months after denervation [48,50]. More recent studies on skeletal muscle of denervated patients and rats showed decreased levels of important factors in stimulation of growth and maintenance of capillaries (VEGF and VEGFR-2) and decreased of the intramuscular capillary number and changes in their morphology and fine structure [32,49,106,108]. It is clinical evidence that paraplegics with upper motor neuron lesion have important alterations in the blood perfusion of the affected limbs with consequent complications as muscle degeneration, pressure ulcers and heterotopic calcifications. In the spastic patients, morphological studies on the skin and skeletal muscle of the plegic limb show changes of the dermal and skeletal muscle capillary network. These are strong contributor factors explaining why force and endurance of leg muscle of spastic paraplegic patients (i.e., with lesion of the upper motoneuron) are suboptimal even after successful rehabilitation strategies such as body weight-supported treadmill training, electrically induced cycle training and FES [5,42,43,79,106].

The analyses of morphological and ultra structural studies on microvasculature in affected limbs from flaccid paraplegics with conus-cauda traumatic lesions show that the alterations of microvasculature in the flaccid paraplegics are even worse and are in full agreement with the observation by Echomyography in LMN denervated muscles (see below). Seven patients of the EU-RISE project who had experienced traumatic lesion of the spinal cord in the Conus Cauda region, developing flaccid paralysis of the thigh skeletal muscle (Conus Cauda syndrome) were biopsied at the quadriceps muscle in between one and three to six years of SCI. Histological, histochemical and ultrastructural studies of muscle biopsies showed progressive muscle atrophy and degeneration, with loss of fibers accompanied by fibrosis in long-standing denervated muscles. In early flaccid paraplegics (up to one year), many regenerated muscle fibers were present, but the intramuscular capillaries were dilated and congested. In long-standing denervation (3 to 6 years), the number of capillaries was reduced and evident structural alterations as thickening and occasional duplication of the basal membrane were demonstrated. In these patients, the processes of capillary repair and neoangiogenesis in skeletal muscle (and in pressure ulcers repair [93] were impaired by deregulation of cytokines, in particular of the vascular endothelial growth factors (VEGF, VEGFR-2). Despite the much more severe fibre atrophy, the capillary alterations were similar to the microvascular modifications in spastic paraplegics suffering from upper motor neuron damage by thoracic level SCI. The results suggest that decrease of vascular endothelial growth factors and receptors and decreased capillary supply are co-responsible of the more severe muscle fibre loss and tissue degeneration in LMN denervated patients. Capillary intramuscular network was, indeed, studied in two other small groups of patients, without or with h-b FES [94]. Vastus lateralis biopsies from four patients with traumatic spinal cord and Conus Cauda lesions from 9 months to 3 years (group 1) were compared to biopsies from two patients with similar lesions since 9.6 and 10.6 years, who underwent 7.7 and 9.3 years of FES training, respectively (group 2). LMN denervated muscles presented decreased mean number of capillaries per fiber in comparison to normal adult muscle. Small vessels showed larger than normal size and endothelial abnormalities with thickening/duplication of basal lamina. In the two 


\section{h-b FES of denervated muscle: management and monitoring}

European Journal Translational Myology - Myology Reviews 1 (3): 91-104, 2010

subjects, who underwent several years of h-b FES, the vascular network appeared almost normalized in ultra structural morphology and number per fiber ratio [94]. Meantime light and electron microscopy analyses showed recovery of myofiber size and ultra structure with significant reduction of fatty infiltration.

We are thus confident that the prevention of muscle tissue degeneration by h-b FES will open new perspectives for: i) recovery of mass and function in SCI and peripheral nerve lesions; ii) maintenance of denervated muscle mass and function after surgical autotransplantation; and iii) reinnervation of human LMN denervated muscles in those cases in which proximal lesions of the peripheral nerves ask for many months of axons regeneration.

\section{New imaging tools for muscle monitoring}

Nuclear magnetic resonance (MR) and Ultrasonography (US) are non invasive imaging techniques that are of common use in muscle physiology, biomechanics, diagnostic and rehabilitation medicine. Cross-sectional imaging including computed tomography and magnetic resonance is the current standard in skeletal muscle imaging. The advantages of these modalities include the ability to image in different planes and to evaluate the distribution of disease and disease burden. Newer magnetic resonance-based techniques also provide functional information in addition to anatomic information. Radiography and ultrasound have a more limited role and are mainly used to detect calcifications and evaluate the texture of skeletal muscle. On the other hands, by ultrasonography has become possible to study in vivo muscle architecture at rest and the changes thereof upon contraction [81]. These are indeed well established for the structural and functional features of human muscle-tendon unit [35]. Furthermore, the inflammatory responses to muscle damage are monitored and quantified by both methods [66].

More recently, two monitoring analyses of muscle responses to LMN denervation and h-b FES recovery, specifically, quantitative Color-3D reconstruction and analysis of the thigh muscles based on data from CT scans was developed in Reykjavik University, Iceland [36-39]) and Functional Echomyography (Quantitative dynamic muscle ultrasonography) at the Interdepartmental Research Center of Myology (cirMYO) of Padua University, Italy [85,86,102,103].

Quantitative color three-dimensional computer tomography

Quantitative color three-dimensional computer tomography imaging was developed to analyze macroscopic and microscopic structural changes of human skeletal muscle based on processing techniques of medical images [36-39]. Spiral computer tomography images and special computational tools are used to isolate the quadriceps muscles and to make 3-dimensional reconstructions of denervated and recovering muscles. Shape, volume and density changes are quantitatively measured on each part of the muscle. Changes in tissue composition within the muscle are visualized associating Hounsfield Unit values of normal or atrophic muscle, fat and connective tissue to different colors (red, pink, yellow, and green, respectively) [36,37,39,57]. The minimal volumetric element (voxel) is ten times smaller than the volume analyzed by needle muscle biopsy. The results of this microstructural analysis are presented as the percentage of different tissues (muscle, loose and fibrous connective tissue, fat) in the total volume of the rectus muscle and, more impressively, displaying layers of voxels that describe the muscle from the cortical epimysium to the muscle core directly on a series of muscle 3-Dimensional reconstructions. In normal and paraplegic patients this new monitoring approach provides information on macroscopic shape, volume, and the increased adipose and fibrous tissue content within the denervated (or aging) muscle. In particular, the change displayed at epimysium level is structurally important and possibly functionally relevant. Muscle restoration induced by two years of home based Functional Electrical Stimulation is documented by the increase of normal muscle tissue from $45 \%$ to $60 \%$ of the whole volume, while connective tissue and fat are reduced of $30 \%$ and $50 \%$ with respect to the pre-treatment values [36-37,39]. These changes are in agreement with the muscle biopsy findings, and self-evident when epimysium thickness is depicted. Color 3-Dimensional imaging of human skeletal muscle is an improved computational approach of medical imaging able to detect not only macroscopic changes of human muscle volume and shape, but also their tissue composition at microscopic level. Complemented with muscle biopsies analyses and functional echomyography they provide detailed description of the behaviors of diseased muscle and of the effectiveness of therapies and rehabilitation strategies.

Human functional echomyography by quantitative dynamic muscle ultrasonography

Beside thickness and texture of the muscles, ultrasonography can detect structural muscle changes caused by neuromuscular disease. Quantitative analysis is the preferred method to determine if ultrasound findings are within normal limits, but normative data are incomplete. Recent studies provide normative muscle ultrasonography data for muscle thickness and echo intensity for five different muscle groups in adults [8]. Bilateral scans of the sternocleidomastoid, biceps brachii/brachialis, forearm flexor group, quadriceps femoris, and tibialis anterior were made in 95 volunteers, aged 17-90 years. Both muscle thickness and echo intensity showed gender differences and a muscle-specific non-linear correlation with age. The 


\section{h-b FES of denervated muscle: management and monitoring}

European Journal Translational Myology - Myology Reviews 1 (3): 91-104, 2010

muscles of the upper extremities showed right-left differences. These data demonstrate the effect of age on muscle characteristics and provide normative values that can be used in clinical practice. Evidence that quantitative ultrasonography of skeletal muscle tissue is a reliable method are accumulating in the medical literature $[7,86]$. A good example is a study in golden retriever muscular dystrophy dogs: the high correlation between interstitial fibrous tissue in muscle biopsies and Echo intensity makes ultrasound a reliable method to determine severity of structural muscle changes [85].

Muscle-dedicated functional radiological techniques for assessing skeletal muscle perfusion by contrastenhanced ultrasound (CEUS) and MR imaging techniques were recently validated to visualize and quantify physiopathologic information about microcirculation within skeletal muscles in vivo and hence establish useful diagnostic tools for muscular diseases [109]. While their sensitivity and repeatability are superior to standard Ultrasonography, CEUS is an invasive technique, $\mathrm{MR}$ is expensive and can not provide the full direct information on behaviors of muscle dynamics and can not be performed frequently or at bed-side. We are exploring the potential of standard non-invasive muscle ultrasonography by taking advantage of its cheapness and of the extensive experience in monitoring anatomy and function of arteries and veins in clinical angiology.

Beside the series of structural and functional analyses validated by the EU-RISE Project, the subjects suffering with Conus Cauda syndrome or peripheral nerve lesions were submitted to Functional echomyography by Quantitative ultrasonography and color echodoppler to analyze muscle size and quality, dynamic contractile characteristics, and perfusion behaviors by resistivity index (RI) and numbers/size of identified intramuscular vessels (perforating arteries) before, during and after voluntary and/or electrical stimulation-induced muscle contractions.

In the Rise2-Italy project we are submitting the enrolled patients with permanent LMN denervation to a new protocol of quantitative ultrasonography (we named Functional Echomyography to stress the dynamic components of the analyses) to evaluate changes in Tibialis Anterior, Deltoid, and Quadriceps muscles undergoing home-based electric stimulation. During a period of 1 year for the first subject (lesion of the right sciatic nerve), 6 months for the second subject (left brachial palsy ) and 8 months for a third subject (Conus Cauda syndrome) we studied the denervated muscle with ultrasound comparing (when possible) the denervated muscles to the contra lateral normal muscle: 1. Gross morphology and sonographic structure; 2. Thickness; 3. Short-term and long-term modifications of the arterial perfusion in response to voluntary and electrical stimulation-induced contractions; 4. Dynamic properties of the voluntary and electrical stimulation-induced contractionrelaxation cycle are monitored.

Morphology and ultrasonographic structure of the denervated muscles changed during the period of stimulation from a pattern typical of muscle atrophy to a pattern which might be considered "normal" when detected in an old patient. Thickness improved significantly more in the middle third than in the proximal and distal third of the denervated muscles, reaching in one year measurements in the first subject approximately the same thickness of the contra lateral normal muscle. In all the measurements, arterial perfusion of the denervated muscle showed a lowresistance pattern with Doppler ultrasonography at rest, and a pulsed pattern after several months of homebased electrical stimulation, more similar to the trifasic high-resistance pattern of the contralateral innervated muscle (Fig. 1). Contraction-relaxation kinetic, measured by recording the movements during electrical stimulation, showed an abnormal behavior in the denervated muscles, in particular during relaxation, which resulted significantly longer than in the normal muscle (880 msec in the denervated muscle vs 240 msec in the contralateral normal muscle). The very high energy needed to stimulate the denervated muscles according to the Vienna h-b FES strategy demonstrates that the explored muscles were still denervated. This pilot study confirms usefulness of Functional Echomyography in the follow-up and the positive effects of h-b FES of denervated and reinnervating muscles. In the later case, Functional echomyography provide information on which muscles or muscle parts are contracting under voluntary or electrical activation $[17,85,86,102,103,111]$.

\section{Perspectives}

Altogether, results of the European Rise Project and early observations of the Rise2-Italy Project suggest that home-based electrical stimulation of the LMN denervated muscles could be extended from the seldom cases of Conus Cauda Syndrome with complete LMN denervation to the more common cases of incomplete SCI and peripheral nerve lesions with clinically relevant results. We are confident that combining sound, but invasive "time zero" and "end-point" analyses [tissue biopsy [18,55,57,58,66,67,89], and Color CT macro-morphometry [36-39,57] with noninvasive, repeatable ultrasound analyses $[7,8,74,85,86,102,103,111]$ some of the following open questions will find a final answer: 1. Reliable evaluation of the extent of muscle denervation and reinnervation; 2. Reliable quantification of the progression of atrophy to degeneration in longstanding muscle denervation; 3. Influence (positive or negative) of electrical stimulation on muscle reinnervation (in well defined sub-groups of patients); 4. Translation to a wider population of healthy and 
h-b FES of denervated muscle: management and monitoring

European Journal Translational Myology - Myology Reviews 1 (3): 91-104, 2010
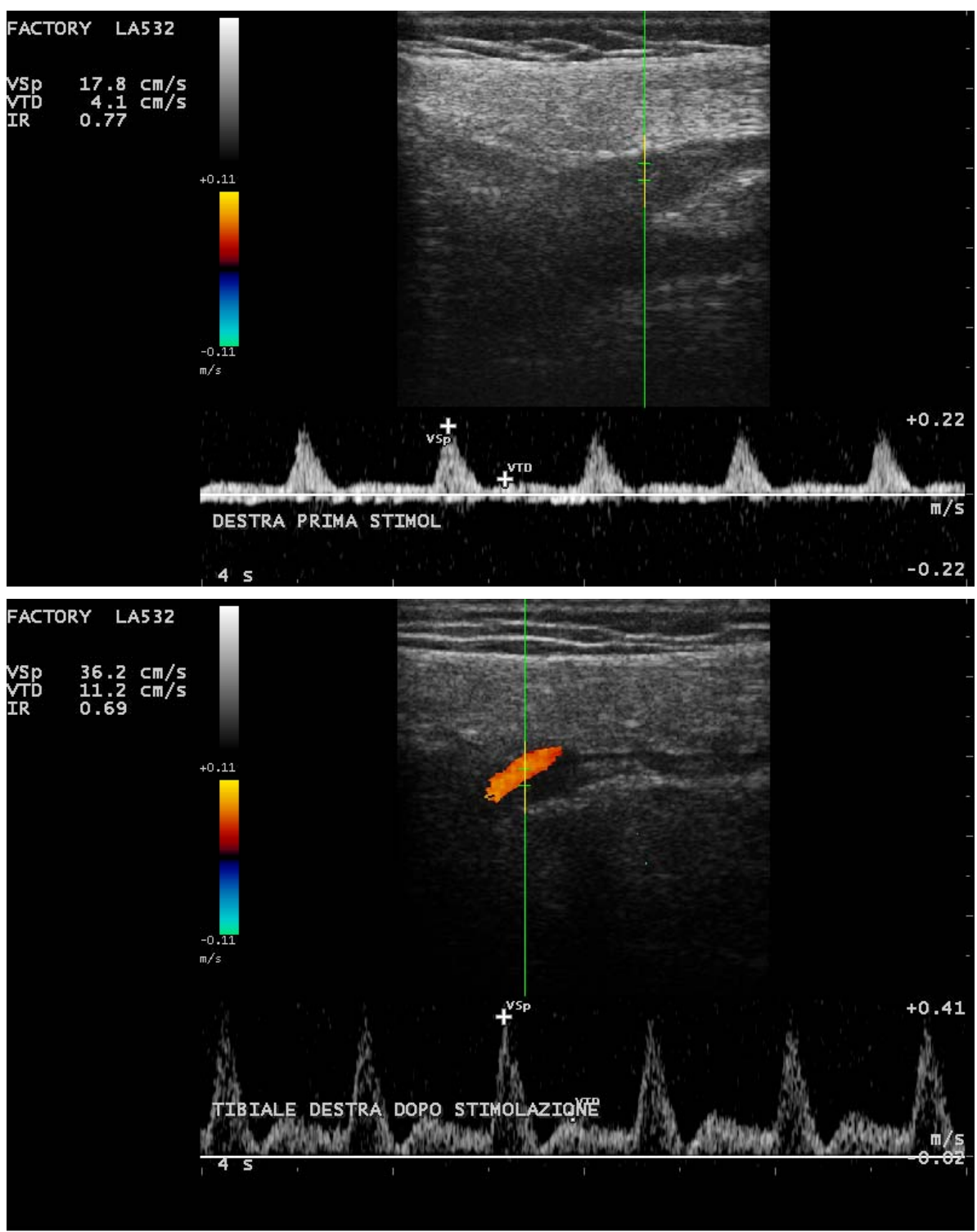

Fig. 1. The Doppler study of the first perforating branch of the Tibialis Anterior artery showed a low resistance curve at rest in the denervated muscle (upper panel), which becames a more high-resistance pattern after several months of h-bFES (lower panel).

diseased elderly persons of the knowledge our interdisciplinary group of European Scientists and Clinicians accumulated during the EU Rise Project by treating the special case of irreversible complete muscle denervation of the thigh muscles and the ongoing Rise2-Italy Project that is extending the homebased FES training to cases of incomplete muscle denervation.

\section{Acknowledgements}

The authors acknowledge support of the EU InterregIV A- Programme Österreich - Slowakei, Project No. SK-AT_080612_N0008 „Mobilität im Alter“, of the Austrian national co-financing of the BM BWK.F.
The EU Commission Shared Cost Project RISE (Contract n. QLG5-CT-2001-02191) and The Austrian Ministry of Science, Vienna (Austria) covered the clinical costs, the production of customized devices and the international management of the project. Italian MIUR funds to the Laboratory of Translational Myology, and Italian C.N.R. funds to the Institute of Neuroscience, University of Padova, Italy, supported the Myo-Bank, light microscopy, morphometry, and costs of data analyses. The MIUR project: RISE2-Italy: Evidence-based optimization of home-based therapeutic functional electrical stimulation (hbt-FES) for human denervated muscle (Prot. n. 2008SJ4MRW) is also supporting the new imaging approaches. 


\section{h-b FES of denervated muscle: management and monitoring}

European Journal Translational Myology - Myology Reviews 1 (3): 91-104, 2010

\section{Corresponding Author}

Prof. Ugo Carraro, Departments of Biomedical Sciences, University of Padova, Viale G. Colombo 3, I-35121 Padova, Italy - Phone: +39 049 8276030; fax +39 049 8276040; E-mail: ugo.carraro@unipd.it

\section{References}

[1] Acharyya S, Butchbach ME, Sahenk Z, Wang H, Saji M, Carathers M, Ringel MD, Skipworth RJ, Fearon KC, Hollingsworth MA, Muscarella $\mathrm{P}$, Burghes AH, Rafael-Fortney JA, Guttridge DC. Dystrophin glycoprotein complex dysfunction: a regulatory link between muscular dystrophy and cancer cachexia. Cancer Cell 2005; 8: 421-432.

[2] Adami N, Biral D, Corbianco S, Zampieri S, Carraro U, Kern H. The fiber types of severely atrophic muscle fibers with nuclear clumps of human 5-year LMN denervated muscle. Basic Appl Myol 2009; 19: 225-228.

[3] Adami N, Kern H, Mayr W, Carraro U, Biral D, Zampieri S. Permanent denervation of rat Tibialis Anterior after bilateral sciatectomy: Determination of chronaxie by surface electrode stimulation during progression of atrophy up to one year. Basic Appl Myol 2007; 17: 237-243.

[4] Adams L, Carlson BM, Henderson L, Goldman D. Adaptation of nicotinic acetylcholine receptor, myogenin, and MRF4 gene expression to long-term muscle denervation. J Cell Biol 1995; 131: 1341-1349.

[5] Adams MM, Ditor DS, Tarnopolsky MA, Phillips SM, McCartney N, Hicks AL. The effect of body weight-supported treadmill training on muscle morphology in an individual with chronic, motor-complete spinal cord injury: A case study. J Spinal Cord Med 2006; 29: 167-171.

[6] Al-Amood WS, Lewis DM, Schmalbruch H. Effects of chronic electrical stimulation on contractile properties of long-term denervated rat skeletal muscle. J Physiol 1991; 441: 243256.

[7] Arts IM, van Rooij FG, Overeem S, Pillen S, Janssen HM, Schelhaas HJ, Zwarts MJ. Quantitative muscle ultrasonography in amyotrophic lateral sclerosis. Ultrasound Med Biol 2008; 34: 354-361. Epub 2007 Oct 26.

[8] Arts IM, Pillen S, Schelhaas HJ, Overeem S, Zwarts MJ. Normal values for quantitative muscle ultrasonography in adults. Muscle Nerve 2010; 41: 32-41.

[9] Ashley Z, Salmons S, Boncompagni S, Protasi F, Russold M, Lanmuller H, Mayr W, Sutherland H, Jarvis JC. Effects of chronic electrical stimulation on long-term denervated muscles of the rabbit hind limb. J Muscle Res Cell Motil 2007; 28: 203-217.

[10] Ashley Z, Sutherland H, Lanmuller H, Russold MF, Unger E, Bijak M, Mayr W, Boncompagni S, Protasi F, Salmons S, Jarvis JC. Atrophy, but not necrosis, in rabbit skeletal muscle denervated for periods up to one year Am J Physiol Cell Physiol 2007; 292: C440-451.

[11] Ashley Z, Sutherland H, Lanmuller H, Unger E, Li F, Mayr W, Kern H, Jarvis JC, Salmons S. Determination of the chronaxie and rheobase of denervated limb muscles in conscious rabbits. Artif Org 2005; 29: 212-215.

[12] Ashley Z, Sutherland H, Russold MF, Lanmüller H, Mayr W, Jarvis JC, Salmons S. Therapeutic stimulation of denervated muscles: the influence of pattern. Muscle Nerve 2008; 38: 875-886.

[13] Bijak M, Rakos M, Hofer C, Mayr W, Strohhofer M, Raschka D, Kern H. Stimulation parameter optimization for FES supported standing up and walking in SCI patients. Artif Organs 2005; 29: 220-223.

[14] Billington L, Carlson BM. The recovery of long-term denervated rat muscles after marcaine treatment and grafting. J Neurol Sci 1996; 144: 147-155.

[15] Biral D, Kern H, Adami N, Boncompagni S, Protasi F, Carraro U. Atrophy-resistant fibers in permanent peripheral denervation of human skeletal muscle. Neurol Res 2008; 30: 137-144.

[16] Biral D, Senter L, Salviati G. Increased expression of dystrophin, beta-dystroglycan and adhalin in denervated rat muscles. J Muscle Res Cell Motil 1996; 17:523-532.

[17] Bizzarini E, Zampa A, Malisan C, Pinzini C, Di Benedetto P, Kern H, Carraro U. Epidemiology and clinical management of Conus-Cauda Syndrome and flaccid paraplegia in Friuli Venezia Giulia: Data of the Spinal Unit of Udine. Basic Appl Myol 2009; 19: 163-167.

[18] Boncompagni S, Kern H, Rossini K, Mayr W, Carraro U, Protasi F. Structural differentiation of skeletal muscle fibers in the absence of innervation in humans. Proc Natl Acad Sci USA 2007; 104: 19339-19344.

[19] Borisov AB, Dedkov EI, Carlson BM. Interrelations of myogenic response, progressive atrophy of muscle fibres, and cell death in denervated skeletal muscle. Anat Rec 2001; 264: 203-218.

[20] Bourke DL, Ontell M. Branched myofibers in long-term whole muscle transplants: a 


\section{h-b FES of denervated muscle: management and monitoring}

European Journal Translational Myology - Myology Reviews 1 (3): 91-104, 2010

quantitative study. Anat Rec 1984; 209: 281288.

[21] Bowden REM, Gutmann E: Denervation and reinnervation of human voluntary muscle. Brain 1944; 67: 273-313.

[22] Bruijin LI, Miller M, Cleveland DW. Unraveling the mechanisms involved in motor neuron degeneration in ALS Annu Rev Neurosci 2004; 27: 723-749.

[23] Carlson BM. The Denervated Muscle: 45 years later. Neurol Res 2008; 30: 119-122.

[24] Carraro U. Modulation of trophism and fiber type expression of denervated muscle by different patterns of electrical stimulation. Basic Appl Myol 2002; 12: 263-272.

[25] Carraro U, Catani C, Dalla Libera L. Myosin light and heavy chains in rat gastrocnemius and diaphragm muscles after chronic denervation or reinnervation. Exp Neurol 1981; 72: 401-412.

[26] Carraro U, Morale D, Mussini I, Lucke S, Cantini M, Betto R, Catani C, Dalla Libera L, Danieli Betto D, Noventa D. Chronic denervation of rat diaphragm: maintenance of fibre heterogeneity with associated increasing uniformity of myosin isoforms. J Cell Biol 1985; 100: 161-174.

[27] Carraro U, Rossini K, Mayr W, Kern H. Muscle fiber regeneration in human permanent lower motoneuron denervation: relevance to safety and effectiveness of FES-training, which induces muscle recovery in SCI subjects. Artif Organs 2005; 29: 187-191.

[28] Carraro U, Rossini K, Zanin ME, Rizzi C, Mayr $\mathrm{W}$, Kern $\mathrm{H}$. Induced myogenesis in long-term permanent denervation: Perspective role in functional electrical stimulation of denervated legs in humans. Basic Appl Myol 2002; 12: 5364.

[29] Carraro U, Sandri M, Zampieri S. Patologia generale del tessuto muscolare scheletrico. In: Patologia Generale. Pontieri GM, Russo MA, Frati L, eds. Piccin Editore, Padova, Italy, in press.

[30] Covault J, Sanes JR. Neural cell adhesion molecule (N-CAM) accumulates in denervated and paralyzed skeletal muscles. Proc Natl Acad Sci USA 1985; 82: 4544-4548.

[31] Dedkov EI, Kostrominova TY, Borisov AB, Carlson BM. Reparative myogenesis in longterm denervated skeletal muscles of adult rats results in a reduction of the satellite cell population. Anat Rec 2001; 263: 139-154.

[32] Dedkov EI, Kostrominova TY, Borisov AB, Carlson BM. Resistance vessel remodeling and reparative angiogenesis in the microcirculatory bed of long-term denervated skeletal muscles. Microvasc Res 2002; 63: 96-114.

[33] Dulhunty AF, Gage PW. Excitation-contraction coupling and charge movement in denervated rat extensor digitorum longus and Soleus muscle. J Physiol 1985; 358: 75-89.

[34] Favier FB, Henri Benoit H, Freyssenet D. Cellular and molecular events controlling skeletal muscle mass in response to altered use. Pflugers Arch - Eur J Physiol 2008; 456: 587600.

[35] Finni T. Structural and functional features of human muscle-tendon unit. Scand J Med Sci Sports 2006; 16: 147-158.

[36] Gargiulo P, Carraro U, Mandl T, Kern H, Zampieri S, Mayr W, Helgason T. Anthropometry of human muscle using segmentation techniques and 3D modelling: applications to lower motor neuron denervated muscle in Spinal Cord Injury. In Preedy VR (ed): The Handbook of Anthropometry: Physical Measures of Human Form in Health and Disease, Springer, Invited, accepted.

[37] Gargiulo P, Kern H, Carraro U, Ingvarsson P, Knútsdóttir S, Gudmundsdóttir V, Yngvason S, Vatnsdal B, Helgason T. Quantitative colour 3D CT imaging of human long-term denervated muscle. Progression to fibrosis of perimysium and a case report of FES recovery. Neurol Res 2010; 32: 13-19.

[38] Gargiulo P, Vatnsdal B, Ingvarsson P, Knútsdóttir S, Gudmundsdóttir V, Yngvason S, Helgason T. Restoration of muscle volume and shape induced by electrical stimulation of denervated degenerated muscles: qualitative and quantitative measurement of changes in rectus femoris using computer tomography and image segmentation. Artif Organs 2008; 32: 609-613.

[39] Gargiulo P, Vatnsdal B, Ingvarsson P, Knútsdóttir S, Gudmundsdóttir V, Yngvason S, Kern H, Carraro U, Helgason T. Computational methods to analyse tissue composition and structural changes in denervated muscle undergoing therapeutic electrical stimulation. Basic Appl Myol/ European Journal of Translational Myology 2009; 19: 157-161.

[40] Gerke V, Creutz CE, Moss SE. Annexins: linking Ca2+ signalling to membrane dynamics. Nat Rev Mol Cell Biol 2005; 6: 449-461.

[41] Germinario E, Esposito A, Midrio M, Betto R, Danieli-Betto D. Expression of sarco(endo)plasmic reticulum $\mathrm{Ca}(2+)$-ATPase slow (SERCA2) isoform in regenerating rat soleus skeletal muscle depends on nerve impulses. Exp Physiol 2002; 87: 575-583. 


\section{h-b FES of denervated muscle: management and monitoring}

European Journal Translational Myology - Myology Reviews 1 (3): 91-104, 2010

[42] Giangregorio LM, Webber CE, Phillips SM, Hicks AL, Craven BC, Bugaresti JM et al. Can body weight supported treadmill training increase bone mass and reverse muscle atrophy in individuals with chronic incomplete spinal cord injury? Appl Physiol Nutr Metab 2006; 31: 283-291.

[43] Graupe D, Cerrel-Bazo H, Kern H, Carraro U. Walking performance, medical outcomes and patient training in FES of innervated muscles for ambulation by thoracic-level complete paraplegics. Neurol Res 2008; 30: 123-130. Review. Erratum in: Neurol Res 2008; 30: 768769.

[44] Gutmann E. The denervated muscle. Prague, Cekia: Publishing House of the Czechoslovak Academy of Sciences; 1962.

[45] Harrison D. Current trends in the treatment of established unilateral facial palsy. In: Functional surgery of the head and neck. E. Karcher, ed. Graz, Austria 1989: 9-16.

[46] Hofer C, Forstner C, Mödlin M, Jäger H, Mayr $\mathrm{W}$, Kern $\mathrm{H}$. In vivo assessment of conduction velocity and refractory period of denervated muscle fibers. Artif Organs 2005; 29: 436-439.

[47] Hofer C, Mayr W, Stöhr H, Unger E, Kern H. A stimulator for functional activation of denervated muscles. Artif Organs 2002; 26: 276-279.

[48] Hudlicka O. Blood flow and oxygen consumption in muscles after section of ventral roots. Circ Res 1997; 20: 570-577.

[49] Hudlicka O. Do changes in the vascular bed contribute to the development of denervation atrophy in skeletal muscle? Basic Appl Myol 2007; 17: 123-124.

[50] Hudlicka O, Renkin EM: Blood flow and blood tissue-diffusion of 86RB in denervated and tenotomized muscles undergoing atrophy. Microvasc Res 1968; 1: 147-157.

[51] Jensen L, Pilegaard H, Neufer PD, Hellsten Y. Effect of acute exercise and exercise training on VEGF splice variants in human skeletal muscle.Am J Physiol Regul Integr Comp Physiol 2004; 287: R397-402. Epub 2004 Apr 29.

[52] Kauhanen MS, Lorenzetti F, Leivo IV, Tukiainen E, Asko-Seljavaara SL. Long-term morphometric and immunohistochemical findings in human free microvascular muscle flaps. Microsurgery 2004; 24: 30-38.

[53] Kauhanen MS, Salmi AM, von Boguslawsky EK, Leivo IV, Asko-Seljavaara SL. Muscle fiber diameter and muscle type distribution following free microvascular muscle transfer: A prospective study. Microsurgery 1998; 18: 137144.

[54] Kern H. Funktionelle Elektrostimulation paraplegischer Patienten. Österr Z Phys Med 1995; 5: 1-79.

[55] Kern H, Boncompagni S, Rossini K, Mayr W, Fanò G, Zanin ME, Podhorska-Okolow M, Protasi F, Carraro U. Long-term denervation in humans causes degeneration of both contractile and excitation-contraction coupling apparatus that can be reversed by functional electrical stimulation (FES). A role for myofiber regeneration? J Neuropathol Exp Neurol 2004; 63: 919-931.

[56] Kern H, Carraro U. Translational Myology Focus on: Clinical Challenges of Functional Electrical Stimulation of Denervated Muscle. Basic Appl Myol/European Journal of Translational Myology 2008; 18: 37-100.

[57] Kern H, Carraro U, Adami N, Biral D Hofer C, Forstner C, Mödlin M, Vogelauer M, Boncompagni S, Paolini C, Mayr W, Protasi F, Zampieri S. Home-based Functional Electrical Stimulation (h-bFES) recovers permanently denervated muscles in paraplegic patients with complete lower motor neuron lesion. Neurorehab Neur Rep 2010, accepted.

[58] Kern H, Carraro U, Adami N, Biral D, Hofer C, Loefler S, Vogelauer M, Mayr W, Rupp R, Zampieri S. One year of home-based Functional Electrical Stimulation (FES) in complete lower motor neuron paraplegia: Recovery of tetanic contractility drives the structural improvements of denervated muscle. Neurol Res 2010; 32: 512.

[59] Kern H, Carraro U, Biral D, Adami N, Zampieri S. Severely atrophic muscle fibers with nuclear clumps survive many years in permanently denervated human muscle. The Open Pathology Journal 2009; 3: 106-110.

[60] Kern H, Hofer C, Mödlin M, Forstner C, Raschka-Högler D, Mayr W, Stöhr H. Denervated muscles in humans: limitations and problems of currently used functional electrical stimulation training protocols. Artif Organs 2002; 26: 216-218. Review.

[61] Kern H, Hofer C, Mödlin M, Mayr W, Vindigni V, Zampieri S, Boncompagni S, Protasi F, Carraro U. Stable muscle atrophy in long-term paraplegics with complete upper motor neuron lesion from 3- to 20-year SCI. Spinal Cord 2008; 46: 293-304. Epub 2007 Oct 23.

[62] Kern H, Hofer C, Mayr W. Protocols for Clinical Work Package of the European Project 


\section{h-b FES of denervated muscle: management and monitoring}

European Journal Translational Myology - Myology Reviews 1 (3): 91-104, 2010

RISE. Basic Appl Myol/European Journal of Translational Myology 2008; 18: 39-44.

[63] Kern H, Hofer C, Mayr W, Carraro U. European Project RISE: Partners, protocols, demography. Basic Appl Myol/European Journal of Translational Myology 2009; 19: 211-216.

[64] Kern H, McKay WB, Dimitrijevic MM, Dimitrijevic MR. Motor control in the human spinal cord and the repair of cord function. Curr Pharm Des.2005;11(11):1429-1439. Review.

[65] Kern H, Hofer C, Strohhofer M, Mayr W, Richter W, Stöhr H. Standing up with denervated muscles in humans using functional electrical stimulation. Artif Organs 1999; 23: 447-452.

[66] Kern H, Rossini K, Carraro U, Mayr W, Vogelauer M, Hoellwarth U, Hofer C. Muscle biopsies show that FES of denervated muscles reverses human muscle degeneration from permanent spinal motoneuron lesion. J Rehabil Res Dev 2005; 42(Suppl 1): 43-53.

[67] Kern H, Salmons S, Mayr W, Rossini K, Carraro U. Recovery of long-term denervated human muscles induced by electrical stimulation. Muscle Nerve 2005; 31: 98-101.

[68] Kobayashi J, Mackinnon SE, Watanabe O. The effect of duration of muscle denervation on functional recovery in the rat model. Muscle Nerve 1997; 20: 858-866.

[69] Kuo GP, Carrino JA. Skeletal muscle imaging and inflammatory myopathies. Curr Opin Rheumatol 2007; 19: 530-535.

[70] Lapalombella R, Kern H, Adami N, Biral D, Zampieri S, Scordari A, di Tullio S, Marini M. Persistence of regenerative myogenesis in spite of down-regulation of activity-dependent genes in long-term denervated rat muscle. Neurol Res 2008; 30: 197-206.

[71] Lotta S, Scelsi R, Alfonsi E, Saitta A, Nicolotti D, Epifani P, Carraro U. Morphometric and neurophysiological analysis of skeletal muscle in paraplegic patients with traumatic cord lesion. Paraplegia 1991; 29: 247-252.

[72] Lotta S, Scelsi L, Scelsi R: Microvascular changes in the lower extremities of paraplegics with heterotopic ossification. Spinal Cord 2001; 39: 595-598.

[73] Mandl T, Meyerspeer M, Reichel M, Kern H, Hofer C, Mayr W, Moser E. Functional electrical stimulation of long-term denervated, degenerated human skeletal muscle: estimating activation using T2-parameter magnetic resonance imaging methods. Artif Organs 2008; 32: 604-608.
[74] Martini R, Ostrowski M, Andreozzi GM, Stramare R, Carraro U. Ultrasonography of medium and small muscle vessels. Basic Appl Myol 2009; 19: 202.

[75] Mayr W, Bijak M, Rafolt D, Sauermann S, Unger E, Lanmüller $H$. Basic design and construction of the Vienna FES implants: existing solutions and prospects for new generations of implants. Med Eng Phys 2001; 23: 53-60.

[76] Meyerspeer M, Mandl T, Reichel M, Mayr W, Hofer C, Kern H, Moser E. Effects of functional electrical stimulation in denervated thigh muscles of paraplegic patients mapped with T2 imaging. MAGMA 2008; 21: 219-226. Epub 2008 Apr 19.

[77] Midrio M. The denervated muscle: facts and hypotheses. A historical review. Eur J Appl Physiol 2006; 98: 1-21.

[78] Mödlin M, Forstner C, Hofer C, Mayr W, Richter W, Carraro U, Protasi F, Kern H. Electrical stimulation of denervated muscles: first results of a clinical study. Artif Organs 2005; 29: 203-206.

[79] Mohr T, Andersen JL, Biering-Sorensen F, Galbo H, Bangsbo J, Wagner A et al. Long-term adaptation to electrically induced cycle training in severe spinal cord injured individuals. Spinal Cord 1997; 35:1-16.

[80] Mussini I, Favaro G, Carraro U. Maturation, dystrophic changes and the continuous production of fibers in skeletal muscle regenerating in the absence of nerve. $\mathrm{J}$ Neuropathol Exp Neurol 1987; 46: 315-331.

[81] Narici M. Human skeletal muscle architecture studied in vivo by non-invasive imaging techniques: functional significance and applications. J Electromyogr Kinesiol 1999; 9: 97-103.

[82] Nightingale EJ, Raymond J, Middleton JW, et al. Benefits of FES gait in a spinal cord injured population. Spinal Cord 2007; 45: 646-657.

[83] Ontell M, Hughes D, Bourke D. Secondary myogenesis of normal muscle produces abnormal myotubes. Anat Rec 1982; 204: 199207.

[84] Paolini C, Quarta M, Nori A, Boncompagni S, Canato M, Volpe P, Allen PD, Reggiani C, Protasi F. Reorganized stores and impaired calcium handling in skeletal muscle of mice lacking calsequestrin-1. J Physiol 2007; 583: 767-784. Epub 2007 Jul 12.

[85] Pillen S, Tak RO, Zwarts MJ, Lammens MMY, Verrijp KN, Arts IMP, van der Laak JA, Hoogerbrugg PM, van Engelen BGM, Verrips 


\section{h-b FES of denervated muscle: management and monitoring}

European Journal Translational Myology - Myology Reviews 1 (3): 91-104, 2010

A. Skeletal muscle ultrasound: correlation between fibrous tissue and echo intensity. Ultrasound Med Biol Volume 2006; 35: 443446.

[86] Pillen S, van Keimpema M, Nievelstein RA, Verrips A, van Kruijsbergen-Raijmann W, Zwarts MJ. Skeletal muscle ultrasonography: Visual versus quantitative evaluation. Ultrasound Med Biol. 2006; 32: 1315-1321.

[87] Robinson A, Tufft N, Lewis DM. A comparison of fibrillation in denervated skeletal muscle of the anaesthetized rat and guinea-pig. J Muscle Res Cell Motil 1991 Jun;12(3):271-80.

[88] Rossato E, Marziali A, Carraro U, Zampieri S, Carniel D, Stramare R, Kern H, Masiero S, Ferraro C. Rise2-Italy Project: Muscle FES after peripheral nerve lesion. Basic Appl Myol 2009; 19: 169-172.

[89] Rossini K, Zanin ME, Podhorska-Okolow M, Carraro U. To stage and quantify regenerative myogenesis in human long-term permanent denervated muscle. Basic Appl Myol 2002; 12: 277-286.

[90] Sandri M, Lin J, Handschin C, Yang W, Arany ZP, Lecker SH, Goldberg AL, Spiegelman BM. PGC-1alpha protects skeletal muscle from atrophy by suppressing FoxO3 action and atrophy-specific gene transcription. Proc Natl Acad Sci USA 2006; 103: 16260-16265.

[91] Scelsi R. Skeletal muscle pathology after Spinal Cord Injury: Our 20 year experience and results on skeletal muscle changes in paraplegics, related to functional rehabilitation. Basic Appl Myol 2001; 11: 75-85.

[92] Scelsi R, Lotta S. Morphological properties of skeletal muscle in spastic paraplegia. Basic Appl Myol 1991; 1: 317-326.

[93] Scelsi R, Lotta S, Sverzellati S, Poggi P. Morphological alterations of microvasculature and neoangiogenesis in the pressure ulcers repair in paraplegics. Basic Appl Myol 2005; 15: 203-208.

[94] Scelsi R, Poggi P, Carraro U, Kern H: Flaccid paraplegia: Improvement of the muscle capillary supply after early-started daily functional electric stimulation (FES) in human permanent lower motoneuron denervation. Basic Appl Myol 2006; 16: 105-107.

[95] Scelsi R, Scelsi L, Lotta S. Morphological changes in the skin microlymphatics in recently injured paraplegics with ileo-femoral venous thrombosis. Paraplegia 1995; 33: 472-475.

[96] Schmalbruch H, Lewis DM. Dynamics of nuclei of muscle fibers and connective tissue cells in normal and denervated rat muscles. Muscle Nerve. 2000; 23: 617-626.

[97] Sferrazza R, Vindigni V, Adami N Carraro U, Mazzoleni F. Myofiber regeneration in a denervated human muscle 3.5 years after posttraumatic free flap reconstruction. Basic Appl Myol 2007; 17: 137-139.

[98] Squecco R, Carraro U, Kern H, Pond A, Adami $\mathrm{N}$, Biral D, Vindigni $\mathrm{V}$, Boncompagni S, Pietrangelo T, Bosco G, Fanò G, Marini M, Abruzzo PM, Germinarlo E, Danieli-Betto D, Protasi F, Francini F, Zampieri S: A subpopulation of rat muscle fibers maintains an assessable excitation-contraction coupling mechanism after long-standing denervation, despite lost contractility. J Neuropath Ex Neurol 2009; 68:1256-1268. Nov 12. [Epub ahead of print] PMID: 19915489.

[99] Squecco R, Francini F, Kern H, et al. L-type $\mathrm{Ca} 2+$ channel mechano-sensitivity in long-term denervated Soleus muscle of the rat. Basic Appl Myol 2005; 15: 187-190.

[100] Squecco R, Kern H, Biral D, Rossini K, Francini F. Mechano-sensitivity of normal and long term denervated soleus muscle of the rat. Neurol Res 2008; 30: 155-159.

[101] Stickler Y, Martinek J, Hofer C, Rattay F. A finite element model of the electrically stimulated human thigh: changes due to denervation and training. Artif Organs 2008; 32:620-624.

[102] Stramare R, Martino L, Masiero S, Kern H, Carraro U. Functional EchoMyography of denervated muscle. Preliminary results. Basic Appl Myol 2009; 19: 206.

[103] Stramare R, Martino L, Rossato E, Zanato R, Masiero S, Carraro U. Functional Echo Myography (Ultra Sonography) of denervated/reinnervating muscle. Basic Appl Myol 2009; 19: 273.

[104] Sunderland S. Nerve and Nerve Injuries, 2nd edition. Edinburgh: Churchill-Livingston 1978.

[105] Takekura H, Kasuga N. Differential response of membrane systems involved in excitationcontraction coupling to early and later postnatal denervation in rat skeletal muscle. J Mus Res Cell Motil 1999; 20: 279-289.

[106] Taylor PN, Ewins DJ, Fox B, Grundy D, Swain ID. Limb blood flow, cardiac output and quadriceps muscle bulk following spinal cord injury and the effect of training for the Odstock functional electrical stimulation standing system. Paraplegia 1993; 31: 303-310.

[107] Viguie CA, Da Xing Lu, Shi-Kai Huang, Rengen H, Carlson BM. Quantitative study of 


\section{h-b FES of denervated muscle: management and monitoring}

European Journal Translational Myology - Myology Reviews 1 (3): 91-104, 2010

the effects of long-term denervation on the extensor digitorum longus muscle of the rat. Anat Rec 1997; 248: 346-354.

[108] Wagatsuma A, Osawa T. Time course of changes in angiogenesis related factors in denervated skeletal muscles. Acta Physiol (Oxf) 2006; 187: 503-509.

[109] Weber MA, Krix M, Delorme S. Quantitative evaluation of muscle perfusion with CEUS and with MR. Eur Radiol 2007 Oct;17(10):2663-74. Epub 2007 Apr 24.
[110] Williams AH, Valdez G, Moresi V, Qi X, McAnally J, Elliot JL, Bassel-Duby R, Sanes JR, Olson EN. MicroRNA-206 delays ALS progression and promotes regeneration of neuromuscular synapses in mice. Science 2009; 326: 1549-1554.

[111] Zanato R. Ecomiografia funzionale del muscolo denervato: risultati preliminari. M.D. Thesis, University of Padova, Italy. 2009. pp. 1-44. 